\title{
БОЛЕЗНЬ ШЕНЛЕЙН-ГЕНОХА В ПРАКТИКЕ ХИРУРГА
}

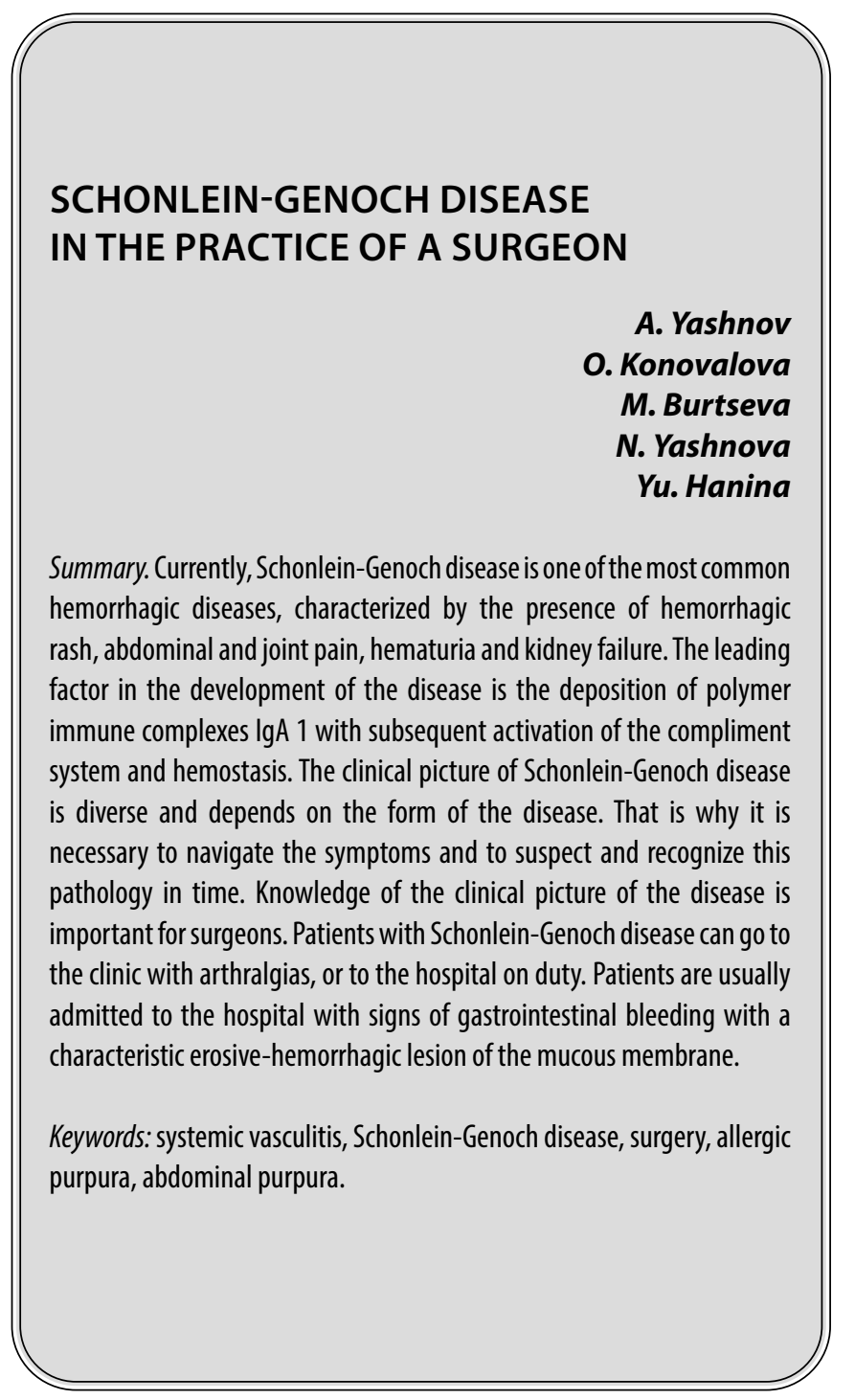

5 олезнь Шенлейн-Геноха (геморрагический васкулит) - это системное асептическое поражение сосудов микроциркуляторного русла с поражением кожных покровов, клубочкового аппарата почек, органов желудочно-кишечного тракта и крупных суставы. Данное заболевание характеризуется наличием геморрагической сыпи, абдоминальными и суставными болями, гематурией и почечной недостаточностью. Необходимо отметить, что в настоящее время болезнь Шенлейн-Геноха одно из самых распространенных геморрагических заболеваний. Вместе с тем, пик заболеваемости приходится на детский возраст и затрагивает возрастную группу от 5 до 15 лет. Распространенность среди данной возрастной группы составляет 3-27 случаев на 100 тысяч детей $[1,2]$. Наряду с эти геморрагический васкулит может наблюдаться и среди взрослого населения.
Яинов Алексей Александрович К.м.н., ассистент, ФГБОУ ВО Читинская государственная медицинская академия alexyashnov@mail.ru

Коновалова Ольга Геннадьевна

К.м.н., доцент, ФГБОУ ВО Читинская государственная медицинская академия

Бурцева Мария Александровна ФГБОУ ВО Читинская государственная медицинская академия

Яинова Надежда Борисовна

ФГБОУ ВО Читинская государственная медицинская академия

Ханина Юлия Сергеевна

К.м.н., дочент, ФГБОУ ВО Читинская государственная медицинская академия

Аннотация. В настоящее время болезнь Шенлейн-Геноха одно из самых распространенных геморрагических заболеваний, характеризующееся наличием геморрагической сыпи, абдоминальными и суставными болями, гематурией и почечной недостаточностью. Ведущим фактором в развитии заболевания определяют отложение полимерных иммунных комплексов IgA1 с последующей активацией системы комплимента и гемостаза. Клиническая картина болезни Шенлейн-Геноха разнообразна и зависит от формы заболевания. Именно поэтому необходимо ориентироваться в симптомах и вовремя заподозрить и распознать данную патологию. Знание клинической картины заболевания важно для врачей хирургов. Пациенты с болезнью Шенлейн-Геноха могут обратиться как в поликлинику с артралгиями, так и в дежурный стационар. В стационар пациенты обычно попадают с признаками желудочно-кишечных кровотечений с характерным эрозивно-геморрагическим поражением слизистой оболочки.

Ключевые слова: системный васкулит, болезнь Шенлейн-Геноха, хирургия, аллергическая пурпура, абдоминальная пупрпура.

До настоящего времени причина возникновения аллергической пурпуры остаётся недостаточно изученной. Болезнь Шенлейн-Геноха - это сложное полиэтиологическое заболевание. В основе данной патологии выделяют ряд триггерных факторов, которые можно подразделить на 4 основных группы [3]:

1. Инфекционные заболевания:

- Острые инфекции дыхательных путей (тонзиллиты, фарингиты, ларингиты, трахеобронхиты);

- Брюшной тиф;

- Паратиф А и В;

Kopb.

2. На фоне приема лекарственных средств:

- Антибактериальных препаратов (пеницилины, макролиды);

Н НВВС; 


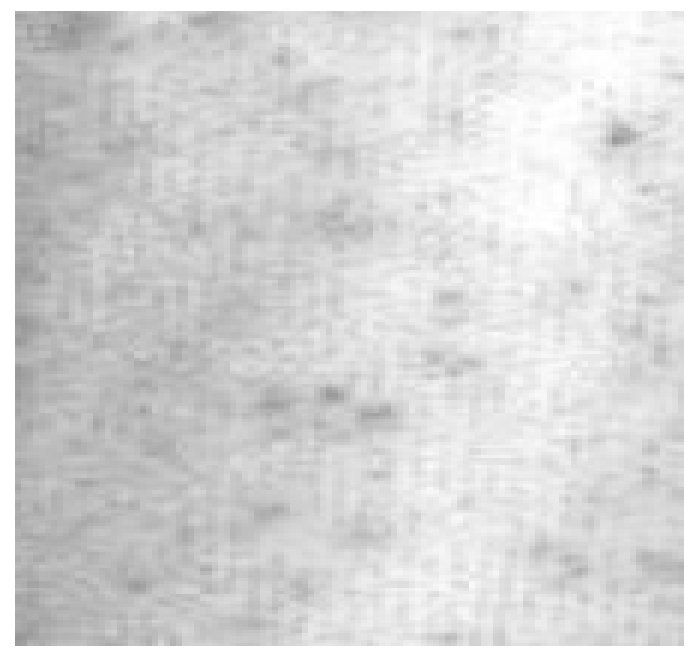

Рис. 1. Кожная форма

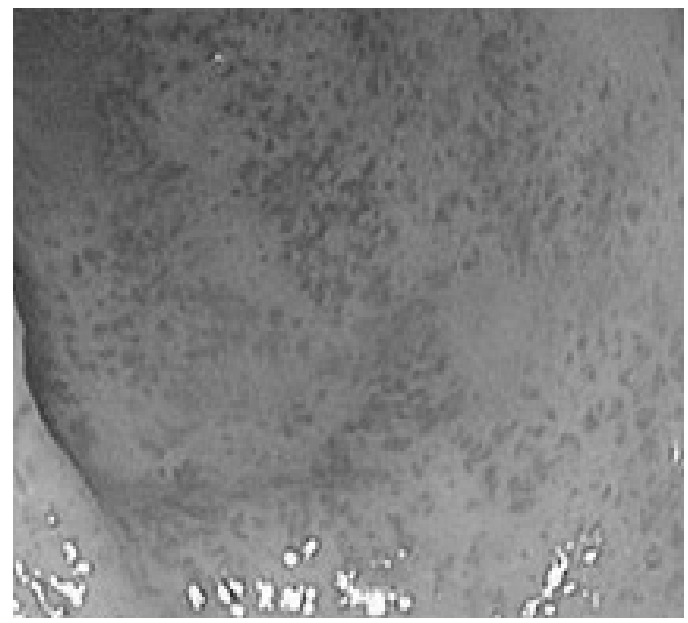

Рис. 2. Геморрагический дуоденит при болезни Шенлейн-Геноха

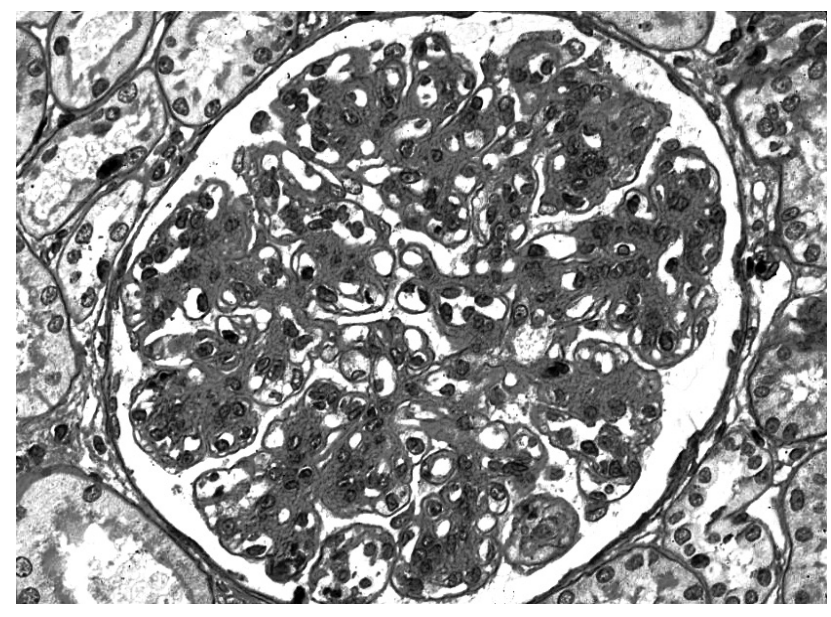

Рис. 3. Гломерулонефрит при геморрагическом васкулите 
- Антиаритмические средства;

- Вакцины ОРВИ.

3. Аллергические реакции и заболевания в анамнезе:

- Аллергический дерматит;

- Полиноз;

Аллергический ринит;

- Пищевые и лекарственные аллергии.

4. Прочие факторы:

- Экзогенные (переохлаждение, укусы насекомых, гиперинсоляция);

- Эндогенные (онкология, беременность, цирроз печени, сахарный диабет).

Необходимо отметить, что патогенез болезни Шенлейн-Генноха остаётся недостаточно изученным. Вместе с тем ведущим фактором в развитии заболевания определяют отложение полимерных иммунных комплексов IgA1 с последующей активацией системы комплимента и гемостаза. Последнее событие приводит к поражению тропных органов и систем. Установлено, что накопление $\lg$ А и С3 компонента комплемента между капиллярами клубочкового аппарата почек сходные c lgA-нефропатиями. Вместе с тем при болезни Шенлейн-Геноха накапливаются в основном полимерным IgA1 c J белком и без секреторного компонента [4].

В зависимости от формы выделяют [4]:

1. Кожная и кожно-суставная:

простая;

- некротическая;

- с холодовой крапивницей и отеками.

2. абдоминальная и кожно-абдоминальная;

3. почечная и кожно-почечная;

4. смешанная

По течению:

1. молниеносное,

2. острое течение,

3. подострое,

4. затяжное,

5. хроническое.

По степени активности:

1. І степень активности характеризуется небольшими кожными высыпаниями;

2. ІІ степень активности проявляется выраженными высыпаниями, синдромом интоксикации, суставным, абдоминальным и мочевым синдромами.

3. III степень активности характеризуется выраженными высыпания, синдромом интоксикации, суставным синдром, абдоминальным и нефритическим синдромами, поражением центральной и периферической нервной системы.
Клиническая картина болезни Шенлейн-Геноха разнообразна и зависит от формы заболевания. Именно поэтому необходимо ориентироваться в симптомах и вовремя заподозрить и распознать данное заболевание. Вместе с тем, с геморрагическим васкулитом может столкнуться любой врач, любой специальности.

Установлено, что болезнь Шенлейн-Геноха характеризуется острым началом и повышением температуры тела до субфебрилитета или фебрилитета. Вместе с тем, у всех заболевших наблюдается геморрагические высыпания, которые приобретают вид пурпуры, возвышающейся над кожной поверхностью. Высыпания могут быть как одиночные, так и сливаться, образуя сплошные элементы с очагами некроза и изъязвлением. Высыпания характеризуются симметричной локализацией на руках, голени, бедрах, ягодицах, крупных суставах, туловище. При ремиссии заболевания пурпура исчезает, оставляя на своем месте небольшую пигментацию [5].

у 70-85\% больных наблюдается суставной синдром, который характеризуется артралгиями, симптомами артрита. Наиболее часто поражаются крупные суставы нижних конечностей (коленные) и верхних конечностей (локтевые, лучезапястные). Вместе с тем, боли в суставах мигрирующие, непостоянные, могут сочетаться с мышечными болями и высыпаниями над поврежденным суставом. Необходимо отметить, что продолжительность артралгии обычно не более недели [5].

Следующим по частоте проявлением болезни Шенлейн-Геноха служит абдоминальный синдром и встречается у $60 \%$ больных. Основные проявления абдоминального синдрома - это болевой синдром (спастические боли во всех отделах живота); диспепсический синдром (тошнота, рвота). Вместе с тем, в ряде случаев наблюдаются желудочно-кишечные кровотечения.

У 26-32\% пациентов с болезнью Шенлейн-Геноха наблюдаются признаки хронического или острого гломерулонефрита. Который появляется после обнаружения других признаков болезни и крайне редко выступает как начальное проявление заболевания. Установлено, что при геморрагическом васкулите может наблюдаться как микрогематурия, так и макрогематурия.

Знание клинической картины заболевания не мало важно для врачей хирургов. Пациенты с болезнью Шенлейн-Геноха могут обратиться как в поликлинику с артралгиями, так и в дежурный стационар. В стационар пациенты обычно попадают с признаками желудочно-кишечного кровотечения с характерным эрозивно-геморрагическим поражением слизистой оболочки. Помимо этого, зачастую ряд пациентов обращается в приемный покой с выраженными болями без чёткой 
локализации. Не редко пациенты оперируются с подозрением на острую хирургическую патологию, что приводит к утяжелению общего состояния. Именно поэтому немало важным является своевременная диагностика данного заболевания. Наряду с этим абдоминальная форма болезни Шенлейн-Геноха может осложняться инвагинацией кишечника, перфорацией стенки кишки с развитием перитонита.

\section{ЛИТЕРАТУРА}

1. Борисова Е. В. Геморрагический васкулит у детей /Педиатрия. — 2004. — № 6. - С. 51-56.

2. Ozen S. The spectrum of vasculitis in children // Best Pract. Res. Clin. Reumatol.— 2002; 16: 411-425.

3. Кикинская Е.Г., Лыскина Г. А. и соавт. Роль инфекции в развитии и течении болезни Шенлейна — Геноха у детей/Актуальные проблемы педиатрии.2006.-C. 299

4. Ярыгин Н. Е. Некоторые вопросы морфологии и классификации аллергических васкулитов. Архив патологии. 1975;37(1):45-52.

5. Семенкова Е. Н. Системные васкулиты. М.: Медицина; 1988.

○ Яшнов Алексей Александрович ( alexyashnov@mail.ru ), Коновалова Ольга Геннадьевна,

Бурцева Мария Александровна, Яшнова Надежда Борисовна, Ханина Юлия Сергеевна.

Журнал «Современная наука: актуальные проблемы теории и практики»

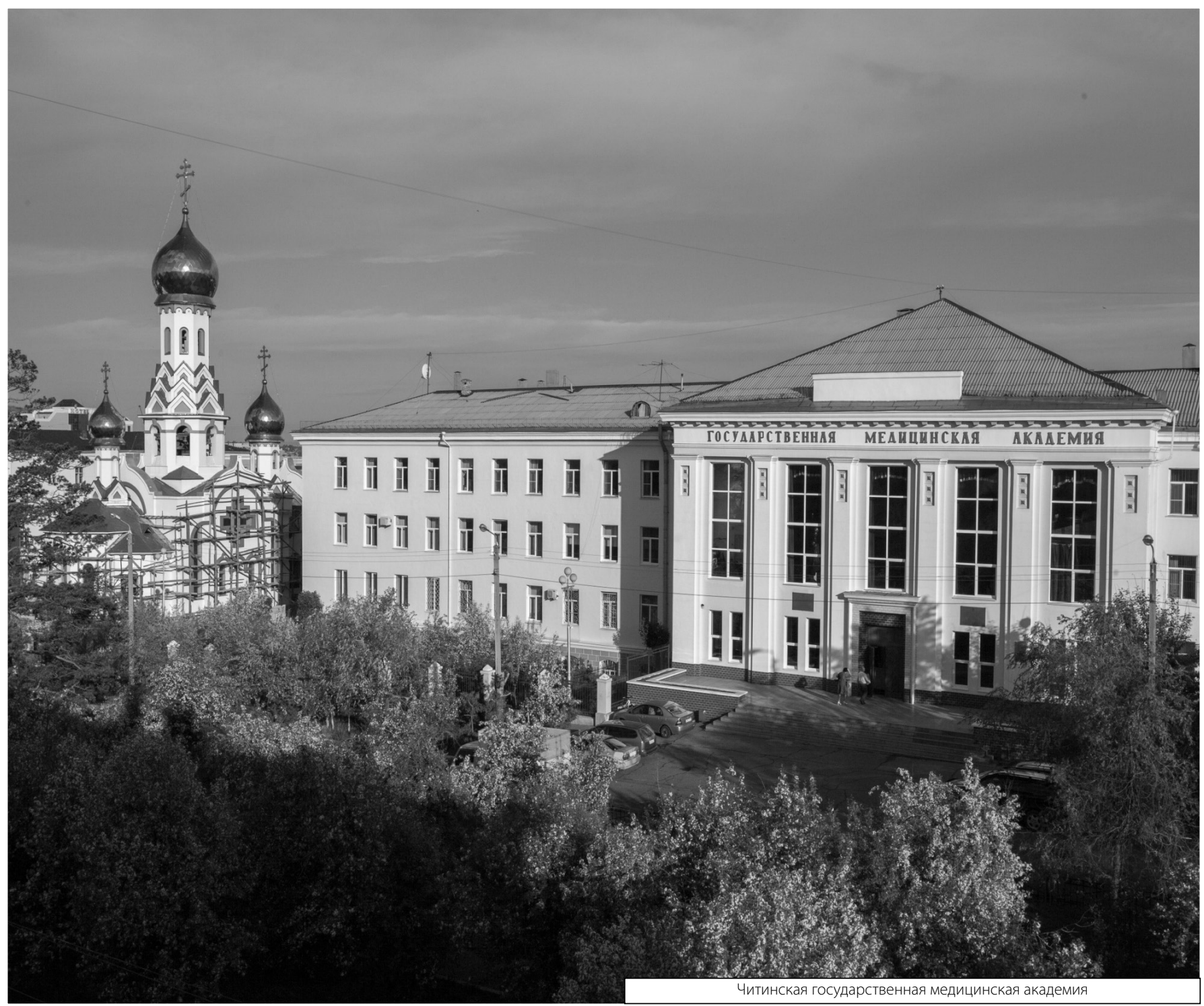

